\title{
Can different fatty acid contents in propofol formulations change bacterial growth?
}

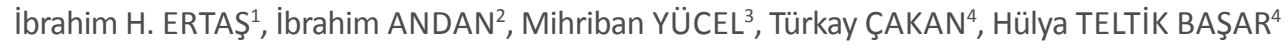

\footnotetext{
${ }^{1}$ Department of Anesthesiology and Reanimation, Ersin Arslan Training and Research Hospital, Gaziantep, Turkey

${ }^{2}$ Department of Anesthesiology and Reanimation, Ahi Evran University Training and Research Hospital, Kırşehir, Turkey

${ }^{3}$ Department of Microbiology, Ankara Training and Research Hospital, Ankara, Turkey

${ }^{4}$ Department of Anesthesiology and Reanimation, Ankara Training and Research Hospital, Ankara, Turkey
}

\section{ABSTRACT}

This study aimed to investigate how Propofol-Lipuro changed the quantity of bacterial growth compared with propofol after changing the lipid content of Propofol-Lipuro. Seven microorganisms (methicillin-resistant Staphylococcus aureus, methicillin-sensitive Staphylococcus aureus, Staphylococcus epidermidis, Escherichia coli, Klebsiella pneumonia, Pseudomonas aeruginosa, and Serratia marcescens), representing different groups that cause hospital-acquired infections and have been already investigated in previous studies, were selected. Each microorganism used in the study was incubated in $5 \%$ sheep blood agar at $36^{\circ} \mathrm{C}$, and reproduction was enabled after 24 h. Three different groups were generated from each microorganism by inoculating the microorganism suspension with10-mL physiological serum (PS), propofol (P), and Propofol-Lipuro (PL). The quantitative growth levels were evaluated by repeated procedures at $36^{\circ} \mathrm{C}$ after 4, 8, 24, and $48 \mathrm{~h}$.

Although a statistically significant difference in terms of quantity of bacterial growth was detected in both propofol formulations (group P and group PL) compared with the control group (PS), no statistically significant difference was detected between the P and PL groups.

No difference was detected in terms of bacterial growth in different lipid contents. In conclusion, this study suggested the use of aseptic methods and administration in accordance with the updated recommendations in the literature while using propofol formulations.

Key words: Bacterial growth, contamination, fatty acids, Propofol-Lipuro

\section{INTRODUCTION}

Two different propofol formulation agents (2,6-diisopropylphenol) have frequently been used in general anesthesia and sedation. They have the same chemical structure, pharmacokinetics and pharmacodynamic characteristics, clinical use, and administration methods (1). Propofol 1\% contains 10\% soybean 0il, 2.25\% glycerol, and 1.2\% purified egg phosphatide (2). The lipid carriers in propofol are 10\% long-chain fatty acids (LCT). However, the lipid carriers in Propofol-Lipuro include 5\% medium-chain fatty acids (MCTs)/5\% LCTs and $2.5 \%$ glycerol (3).

Propofol emulsions strongly support bacterial growth and cause endotoxin contamination $(4,5)$. Some of the emulsions currently used include $0.005 \%$ ethylenediaminetetraacetic acid (EDTA), which delays bacterial growth (6). The concentration of EDTA in the emulsions was shown to have antibacterial characteristics with a delayed increase in millimetric colony-forming units (CFUs). Clinical studies have shown that the aqueous phase of free propofol in propofol injections was correlated with the degree of pain (7). Propofol-Lipuro was developed to decrease injection pain with the inclusion of MCTs. 
The present study aimed to investigate whether different lipid carriers increased bacterial growth in propofol and Propofol-Lipuro preparations without an antimicrobial agent. These agents were inoculated with seven different microorganisms in an experimental environment, and bacterial growth amounts and growth times over different periods were compared for each type of microorganism.

\section{METHODS}

This study was approved by the ethics committee of Ankara Training and Research Hospital on July 24, 2013 (No: 513-4293). The effects of Propofol 1\% (Fresenius Kabi, Graz, Austria) and Propofol-Lipuro 1\% (B. Braun, Melsungen, Germany) on microorganismal growth were compared after experimental contamination with seven different types of microorganisms. Poliflex $0.9 \%$ isotonic sodium chloride solution (Polifarma, Istanbul, Turkey) was used as the control.

The selection of microorganism species was based on two important factors: representation of different groups and having been isolated as anesthesia-rooted infection agents in previous studies (8) (9). Based on these criteria, the microorganisms included in the study were methicillin-resistant Staphylococcus aureus (MRSA), methicillin-sensitive Staphylococcus aureus (MSSA), Staphylococcus epidermidis, Escherichia coli, Klebsiella pneumonia, Pseudomonas aeruginosa, and Serratia marcescens.

The microorganisms were seeded in 5\% sheep blood agar (ORBAK, Ankara, Turkey), and reproduction of plaques was enabled by incubating for $24 \mathrm{~h}$ at $36^{\circ} \mathrm{C}$. Plaques were evaluated for single-type reproduction at the end of incubation period.

The bacterial suspension of $0.5 \%$ McFarland $\left(0.5 \times 10^{8}\right.$ CFU/ $\mathrm{mL}$ concentration) was prepared using $1 \mathrm{~mL}$ of $0.9 \%$ sterilized physiological serum (PS) in tapped sterilized glass tubes for each microorganism after confirming the purity of reproduction in the plaques. A McFarland gauge was used to evaluate the concentration.

Next, $5 \mathrm{~mL}$ of sterilized PS was prepared in another sterilized glass tube for each microorganism. A dilution of 1:50 was achieved by adding $100 \mu \mathrm{L}$ from the first tube after vortexing, and bacterial suspensions in a dilution of $10^{6}$ CFUs/mL were obtained. Microorganism suspensions $(0.1 \mathrm{~mL})$ from each microorganism were taken after vortexing, and three different groups were generated by inoculating the suspensions with $10-\mathrm{mL}$ physiological serum (PS group (control group)), Propofol-Lipuro (PL group), and propofol (P group) in three different tubes.

The obtained concentration was $10^{4} \mathrm{CFUs} / \mathrm{mL}$ after generating a 1:100 dilution. Each suspension was vortexed for $1 \mathrm{~min}$ after adding the microorganisms. Then, $0.01-\mathrm{mL}$ plantation was performed in 5\% sheep blood agar medium. The suspensions were preserved at $20^{\circ} \mathrm{C}$. Vortexing and plantation procedures were repeated after 4 , 8,24 , and $48 \mathrm{~h}$. The quantitative growth amount was evaluated after incubation for $24 \mathrm{~h}$ at $36^{\circ} \mathrm{C}$ in the sheep blood agar medium.

\section{Statistical analysis}

The Statistical Package for the Social Sciences for Windows 19.0 was used for the statistical analyses of results. Descriptive statistics (mean and standard deviation) were obtained in the evaluation of the study data, and variant analysis (repeated-measures test) was used in repeated measurements of two agents in the comparison of the intergroup follow-up times and CFU level between the groups. The group differences were determined using the least significant difference test at the end. The results were evaluated at a 95\% confidence interval and significance of $P<0.05$.

\section{RESULTS}

A significant difference was detected with respect to the CFU level in repeated measurements of two factors with variant analysis ( $P$ $<0.001)$. A difference was detected in the intragroup time (FU levels $(P=0.040)$ (Table 1).

Statistically significant differences were detected in the CFUs/mL levels between groups $P S$ and $P L$, and groups $P S$ and $P(P=0.020$ and $P=0.002)$; however, no statistically significant difference was detected between groups $P L$ and $P(P=0.259)$ (Table 2).

The bacterial growth quantities were demonstrated after taking the logarithm of the CFU levels in the three groups. No significant change was observed in the numbers of MRSA and MSSA in the 
TABLE 1: Comparison of the descriptive statistics of log of CFU level with respect to the intragroup and intergroup times.



\begin{tabular}{|c|c|c|c|c|}
\hline Groups & & Differences between the means & Standard error & $P$ \\
\hline \multirow[t]{2}{*}{ PS } & PL & $-0.686^{*}$ & 0.269 & .020 \\
\hline & $\mathrm{P}$ & $-1.000^{*}$ & 0.269 & .002 \\
\hline \multirow[t]{2}{*}{ PL } & PS & $0.686^{*}$ & 0.269 & .020 \\
\hline & $\mathrm{P}$ & -0.314 & 0.269 & .259 \\
\hline \multirow[t]{2}{*}{$P$} & PS & $1.000 *$ & 0.269 & .002 \\
\hline & $\mathrm{PL}$ & 0.314 & 0.269 & .259 \\
\hline
\end{tabular}

PS group considering the CFUs/mL levels with time; however, a decrease in the number of $S$. epidermidis and an increase in other bacteria were detected (Figure 1).

Propofol-Lipuro did not increase the reproduction amount of MRSA and MSSA at the end of $48 \mathrm{~h}$ in the PL group (Figure $1 \mathrm{~A}$ and $1 \mathrm{C}$ ). Significant increases in the numbers of colonies of $S$. epidermidis, E. coli, K. pneumonia, and S. marcescens were observed, particularly after $8 \mathrm{~h}$ in the reproduction curve (Figure 1B and 1D-1F). A difference was detected in the reproduction graphics of P. aeruginosa compared with other microorganisms. Although an increase was noted during $0-4 \mathrm{~h}$ in the other groups, the period was stable in $P$. aeruginosa. Followed by a stable period, increased reproduction levels of $P$. aeruginosa were found during $4-8 \mathrm{~h}$ and 24-48 h (Figure 1G).

An increase was seen in all microorganisms in the $\mathrm{P}$ group at the end of $48 \mathrm{~h}$. The comparison of the CFUs/mL levels of MRSA according to time showed an increase until $4 \mathrm{~h}$ in the $\mathrm{P}$ group compared with the PL group. However, no increase was detected in the PL group. A decrease in the P group and an increase in the PL group was detected between 4 and $8 \mathrm{~h}$. The increase continued in the $P$ group after $24 \mathrm{~h}$. However, a decrease was detected in the $P L$ group (Figure 1A). The reproduction curves of $S$. epidermidis, MSSA, E. coli, K. pneumonia, and P. aeruginosa were similar in both propofol formulations (Fig. 1B-1E and 1G). The reproduction curve of $S$. marcescens showed an increase in both groups at the end of $24 \mathrm{~h}$; however, the increase in reproduction and stable periods during $0-4,4-8$, and $8-24 \mathrm{~h}$ differed (Figure 1F).

\section{DISCUSSION}

Propofol and Propofol-Lipuro, which have been used in anesthesia practice, have been known to behave as a medium facilitating the reproduction of microorganisms due to their chemical characteristics $(10,11,12)$. A report released in the United States in 1990 by the Centers for Disease Control indicated that extrinsic contamination of propofol was possible; therefore, it recommended 


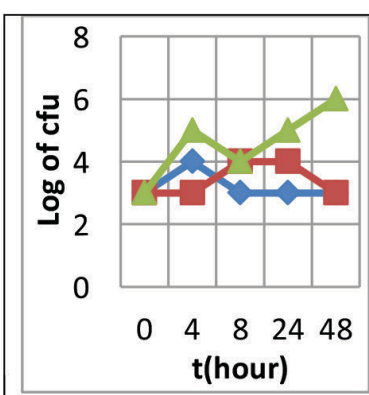

(A) MRSA

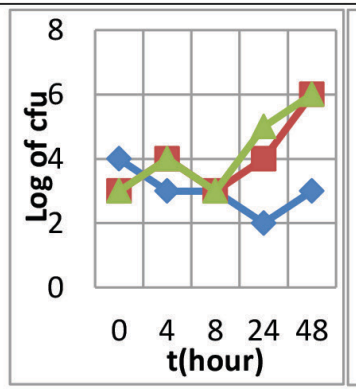

(B) S. epidermidis

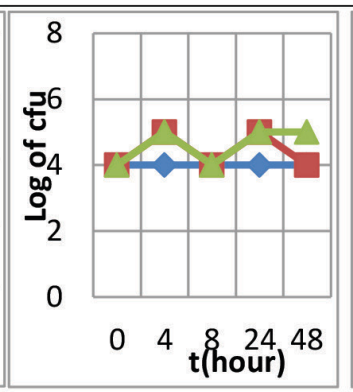

(C) MSSA

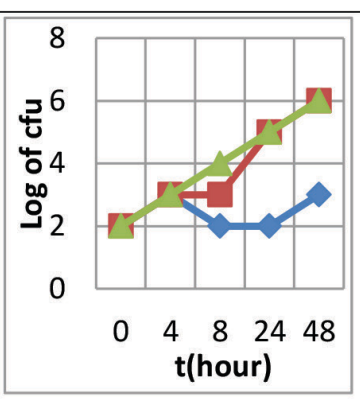

(D) E. coli

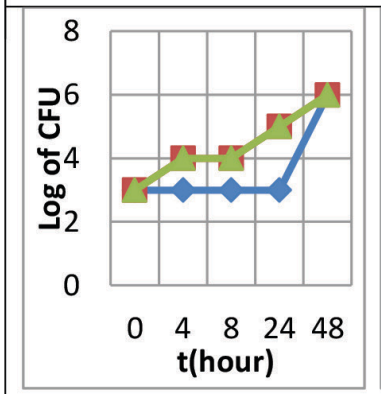

(E) K. pneumonia

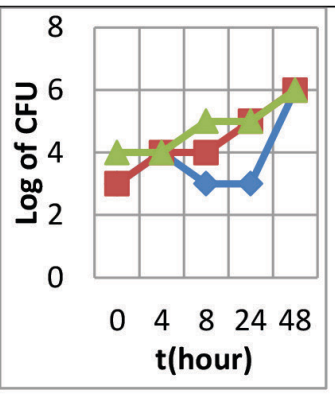

(F) S. marcescens

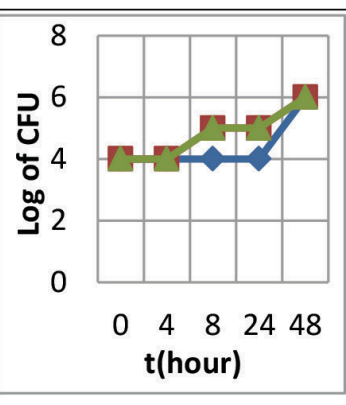

(G) P. aeruginosa

FIGURE 1: Bacterial growth curves of the microorganisms obtained by incubation at $36^{\circ} \mathrm{C}$ in the PS, PL, and P groups. P, Propofol; PL, Propofol-Lipuro; PS, physiological serum.

the aseptic use of drug, immediate administration of drug after opening in sterile conditions, and use of ampule content within $6 \mathrm{~h}$ or dispose (13). Studies conducted in subsequent years particularly recommended the preservation of propofol formulations in sterilized and closed-end injectors rather than as open ampules, in addition to the previous recommendations (14).

Sosis et al. investigated the growth of $S$. aureus in bactericide-free sheep blood agar containing propofol, thiopental, methohexital, etomidate, and $0.9 \%$ saline during $0-3,6-6,6-21,21-24$, and after $27 \mathrm{~h}$, and reported that only propofol had a perfect environment for the rapid growth of $S$. aureus (15). Similar to the study by Joubert et al., PS was used as the control group in this study (16). No significant increase was detected compared with the initial colonization levels in the PS group after 4, 8, and 24 h; however, a significant increase was detected in the number of colonies after $48 \mathrm{~h}$.

Three induction agents (propofol, thiopental, and alfaxalone) were investigated in a previous study, and it was observed that $S$. aureus and $E$. coli rapidly reproduced in propofol solution after $6 \mathrm{~h}$, and the reproduction of E. coli was very rapid after $24 \mathrm{~h}$ (14), consistent with the results of the present study regarding the colonization trend in E. coli.

Apan et al. found that the growth of $E$. coli was less affected compared with other agents when an agent known to inhibit E. coli reproduction (remifentanil) was added to propofol. They emphasized that the lipid content of propofol highly facilitated bacterial growth, and attentive aseptic conditions must be observed while using propofol to avoid any possible contamination (17). A study investigating how heat and the inclusion of lidocaine into propofol affected bacterial contamination showed that less bacterial growth was detected in samples preserved in sterilized injectors compared with those preserved as open ampules. Lidocaine and heat did not significantly change the bacterial growth, and injectors must be prepared for single use only (18).

Yamakage et al. contaminated two different propofol products, one with and one without EDTA, at $20^{\circ} \mathrm{C}-25^{\circ} \mathrm{C}$ in soybean 
or Sabouraud's agar using E. coli, S. aureus, P. aeruginosa, S. marcescens, B. cepacia, and C. albicans, and measured the CFU levels during 6-12, 12-24, and 48 h. E. coli and B. cepacia reproduction was detected in the EDTA-containing formulation; however, $S$. marcescens reproduction was detected in both formulations. The authors concluded that although EDTA had a bactericidal effect, it could not completely inhibit the growth environment in propofol (19). In this study, an increase in S. marcescens was observed at all time points. However, no change in the number of $P$. aeruginosa colonies was detected between $0-4$ and $8-24 \mathrm{~h}$; an increase in the number of colonies was detected during $4-8 \mathrm{~h}$.

Zorrilla-Vaca et al. identified 58 studies conducted between 1989 and 2014 associated with propofol-related infections. They showed that propofol-associated hospital-acquired infections were a significant public health problem, and recommended that more observation and studies should be conducted to decrease the potential harm of contaminated propofol. They suggested that health workers must focus on hygiene precautions and prefer antimicrobial-containing propofol solutions to decrease contamination risk. The safe use of propofol would significantly improve outcomes (20).

The recommendations for the use of propofol solutions have a significant role in anesthesia practice and must be followed as emphasized in the literature. The recommendations for use, particularly after 2005, included the use of $20 \mathrm{~mL}$ ampules in operating rooms, $50 \mathrm{~mL}$ flacons in intensive care units and one ampule for one patient. Furthermore, unused propofol solution should be disposed of, propofol solutions involving EDTA should be preferred, injection regions that are regarded to be a dead space region should be changed within $12 \mathrm{~h}$, and health workers preparing the drugs should maintain proper hand hygiene $(6,12)(21)$.

\section{CONCLUSIONS}

A statistically significant increase was noted in the number of microorganism colonies in contaminated propofol and PropofolLipuro compared with PS. No statistically significant difference was detected between propofol and Propofol-Lipuro regarding the number of microorganism colonies, except with MRSA and MSSA.
An important limitation of the present study was that the test protocol was applied only once. The results of the present study would be more reliable if the test protocol is repeated three times. More studies should be conducted to investigate the nonsignificant difference in the reproduction quantity of MRSA and MSSA in the Propofol-Lipuro group, which has not been reported to date. In view of these results, the present study suggests the use of aseptic methods and administration in accordance with the updated recommendations in the literature while using propofol agents for decreasing contamination.

\section{REFERENCES}

1. Aun CS. New i.v. agents. Br J Anaesth. 1999 Jul;83(1):29-41. PubMed PMID: 10616331.

2. VJ C. Principles of anesthesiology: general and regional anesthesia 3ed. Philadelphia: Lea \&Febiger 1993.

3. Melton MS, Nielsen KC, Tucker M, et al. New medications and techniques in ambulatory anesthesia. Anesthesiol Clin. 2014 Jun;32(2):463-85. doi: 10.1016/j.anclin.2014.02.003. PubMed PMID: 24882131.

4. Chen SH, Kung CC, Fung ST. Endotoxemia due to propofol contamination in four consecutive patients. J Formos Med Assoc. 2014 May;113(5):328-9. doi: 10.1016/j.jfma.2013.08.012. PubMed PMID: 24080015.

5. Tulgar S, Alasehir EA, Selvi O. [The antimicrobial activity of ephedrine and admixture of ephedrine and propofol: an in vitro study]. Rev Bras Anestesiol. 2018 Jan - Feb;68(1):69-74. doi: 10.1016/j.bjan.2017.08.001. PubMed PMID: 28870386; English.

6. Tüzüner F. İntravenöz Anestezikler ve Verilim Sistemleri. In: Tüzüner F, editor. Anestezi Yoğun Bakım Ağrı. Vol. 1.1 ed. Ankara: MN Medikal- Nobel Tıp Kitap Sarayl; 2010. p. 181-184.

7. Doenicke AW, Roizen MF, Rau J, et al. Reducing pain during propofol injection: the role of the solvent. Anesth Analg. 1996 Mar;82(3):472-4. PubMed PMID: 8623945.

8. Fukada T, Ozaki M. Microbial growth in propofol formulations with disodium edetate and the influence of venous access system dead space. Anaesthesia. 2007 Jun;62(6):575-80. doi: 10.1111/j.13652044.2007.05002.x. PubMed PMID: 17506735.

9. Crowther J, Hrazdil J, Jolly DT, et al. Growth of microorganisms in propofol, thiopental, and a 1:1 mixture of propofol and thiopental. Anesth Analg. 1996 Mar;82(3):475-8. PubMed PMID: 8623946.

10. Henry B, Plante-Jenkins C, Ostrowska K. An outbreak of Serratia marcescens associated with the anesthetic agent propofol. Am J Infect Control. 2001 Oct;29(5):312-5. PubMed PMID: 11584257.

11. Veber B, Gachot B, Bedos JP, et al. Severe sepsis after intravenous injection of contaminated propofol. Anesthesiology. 1994 Mar;80(3):712-3. PubMed PMID: 8141478.

12. Bennett SN, McNeil MM, Bland LA, et al. Postoperative infections traced to contamination of an intravenous anesthetic, propofol. N Engl J Med. 1995 Jul 20;333(3):147-54. doi: 10.1056/ NEJM199507203330303. PubMed PMID: 7791816. 
13. Centers for Disease C. Postsurgical infections associated with an extrinsically contaminated intravenous anesthetic agent-California, Illinois, Maine, and Michigan, 1990. MMWR Morb Mortal Wkly Rep. 1990 Jun 29;39(25):426-7, 433. PubMed PMID: 2113169 .

14. Strachan FA, Mansel JC, Clutton RE. A comparison of microbial growth in alfaxalone, propofol and thiopental. J Small Anim Pract. 2008 Apr;49(4):186-90. doi: 10.1111/j.1748-5827.2007.00473.x. PubMed PMID: 18194193.

15. Sosis MB, Braverman B. Growth of Staphylococcus aureus in four intravenous anesthetics. Anesth Analg. 1993 Oct;77(4):766-8. PubMed PMID: 8214662.

16. Joubert KE, Picard J, Sethusa M. Inhibition of bacterial growth by different mixtures of propofol and thiopentone. J S Afr Vet Assoc. 2005 Jun;76(2):85-9. PubMed PMID: 16108527.

17. Apan TZ, Apan A, Sahin S, et al. Antibacterial activity of remifentanil and mixtures of remifentanil and propofol. J Clin Anesth. 2007 Aug;19(5):346-50. doi: 10.1016/j.jclinane.2007.02.005. PubMed PMID: 17869984.
18. Aydin N, Aydin N, Gultekin B, et al. Bacterial contamination of propofol: the effects of temperature and lidocaine. Eur J Anaesthesiol. 2002 Jun;19(6):455-8. PubMed PMID: 12094922.

19. Yamakage $M$ YH, Namiki A. Growth of Micro-organisms in Two Propofol Products at Room Temperature. The Journal of Japan Society for Clinical Anesthesia. 2005;25(2):154-161. doi: http://doi. org/10.2199/jjsca.25.154.

20. Zorrilla-Vaca A, Arevalo JJ, Escandon-Vargas K, et al. Infectious Disease Risk Associated with Contaminated Propofol Anesthesia, 1989-2014(1). Emerg Infect Dis. 2016 Jun;22(6):981-92. doi: 10.3201/eid2206.150376. PubMed PMID: 27192163; PubMed Central PMCID: PMCPMC4880094.

21. Muller AE, Huisman I, Roos PJ, et al. Outbreak of severe sepsis due to contaminated propofol: lessons to learn. J Hosp Infect. 2010 Nov;76(3):225-30. doi: 10.1016/j.jhin.2010.06.003. PubMed PMID: 20692067. 